\title{
Rising options in advanced soft tissue sarcomas: present and future treatment sequences
}

José Casanova*

Soft tissue sarcomas (STS) are a complex and heterogeneous group of rare solid tumors of mesenchymal origin, currently encompassing more than 80 histological subtypes. Localized tumors are managed by wide excisional surgery with or without adjuvant radiotherapy, whereas cytotoxic chemotherapy is the mainstay of treatment for advanced or metastatic disease.

Despite considerable heterogeneity in terms of the origin, clinical presentation and treatment response of STS tumors, until relatively recently, nearly all subtypes had been considered collectively for clinical trial purposes and were treated in the same manner. For 35 years, anthracyclines and ifosfamide were the only approved options for systemic treatment of STS (Figure 1, see overleaf). The approval of trabectedin in Europe in 2007 ushered in a new era in advanced sarcoma management. Over the past decade, other cytotoxic and targeted agents have been approved and many more are in development, including some that are challenging doxorubicin's position as standard first-line therapy of advanced or metastatic disease. During this same time frame, international collaboration in the sarcoma field has facilitated the design and conduct of numerous randomized controlled trials in advanced STS. Increasingly, clinical trials are recruiting specific histological subtypes and/or conducting subgroup analyses to identify subtypes with greater or less sensitivity to systemic therapy.

At the Annual Meeting of the Connective Tissue Oncology Group in November 2016, a symposium was held entitled Rising Options in Advanced STS: Present and Future Treatment Sequences. As the title suggests, the expert panel analyzed the present and near future of sarcoma treatment. Using case studies of patients with STS, experts reviewed treatment approaches based on previous standards, speculated on ways in which treatment might have differed according to today's standards and previewed potential future standards of treatment for advanced STS. It was my pleasure to chair the meeting and to share these proceedings.

\section{Financial \& competing interests disclosure}

The author has no relevant affliations or financial involvement with any organization or entity with a financial interest in or financial conflict with the subject matter or materials discussed in the manuscript. This includes employment, consultancies, honoraria, stock ownership or options, expert testimony, grants or patents received or pending, or royalties.

Writing assistance was provided by Content Ed Net (Madrid, Spain) with funding from PharmaMar, Madrid, Spain.

*Clínica Universitária de Ortopedia, Serviço de Ortopedia, Unidade de Tumores do Aparelho Locomotor, Centro Hospitalar e Universitário de Coimbra, Portugal; jmcasanova@fmed.uc.pt; jmpscasanova@gmail.com 


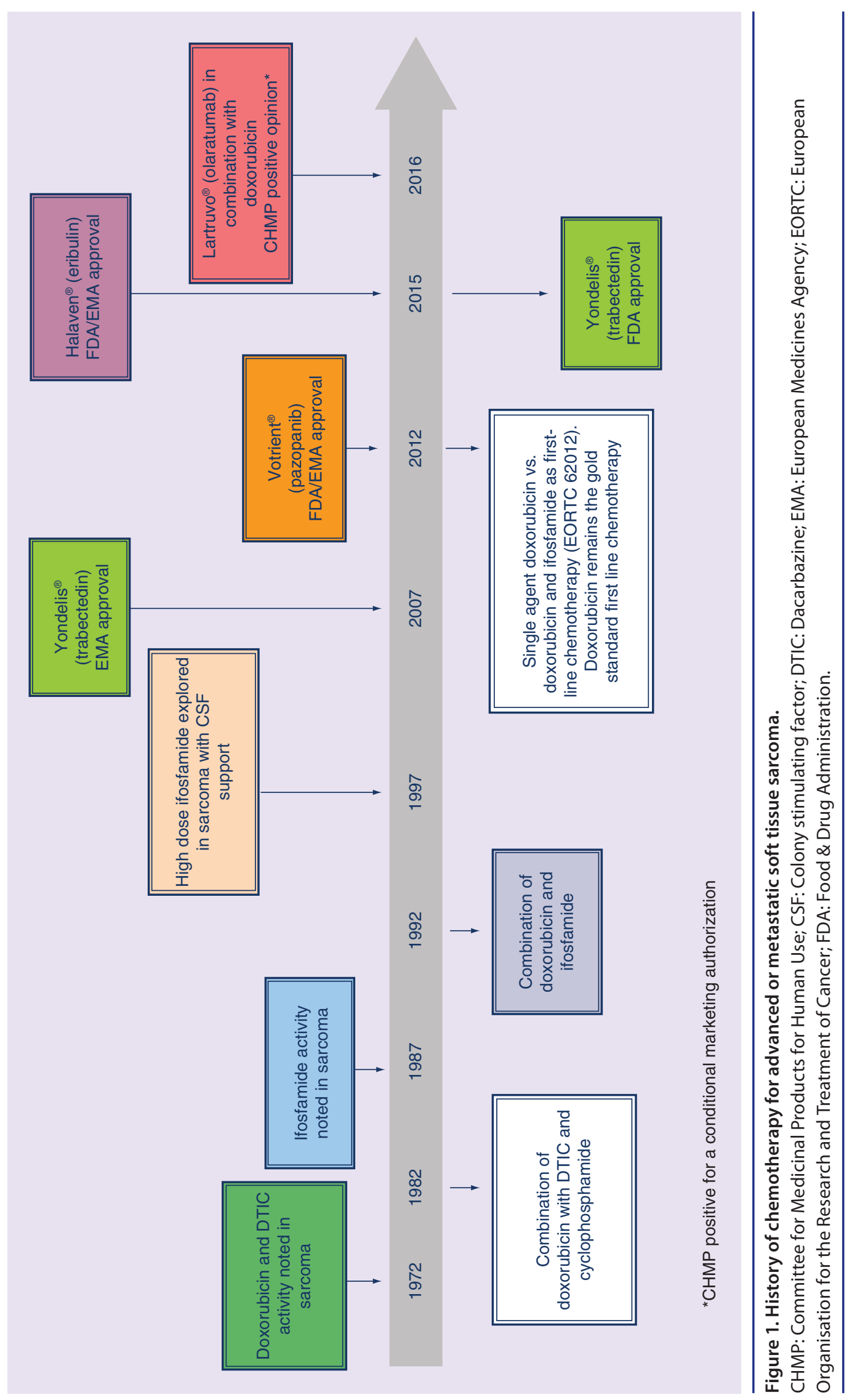

